\title{
A ENTROPIA NO ENSINO MÉDIO: UTILIZANDO CONCEPÇÓES PRÉVIAS DOS ESTUDANTES E ASPECTOS DA EVOLUÇÃO DO CONCEITO
}

\section{Entropy in High Schools: using students spontaneous reasoning and aspects of the concept evolution}

\author{
Silvia Cristina Teodoro Covolan ${ }^{I}$ \\ Dirceu da Silva ${ }^{2}$
}

\begin{abstract}
Resumo: Dentro de uma perspectiva construtivista, a pesquisa em questão pretendeu avaliar a evolução da aprendizagem de alunos do Ensino Médio, quando colocados em contato com o conceito de entropia em situaçôes cotidianas, por meio de atividades (com base no cotidiano) e textos didáticos. Nossa estratégia se baseou nas concepçóes prévias dos estudantes e na utilização do processo de construção e desenvolvimento do conceito como pano de fundo na contextualização dos conhecimentos desenvolvidos. Os dados foram coletados de um grupo de dez estudantes através de pré e pós-teste e analisados segundo a técnica de análise de conteúdo. Como conclusão, foi possível verificar uma evolução significativa na maioria dos estudantes da nossa amostra.
\end{abstract}

Unitermos: ensino de Física, Entropia, Construtivismo, Evolução Conceitual.

Abstract: From alnside of constructivist perspective, the research in question intended to evaluate the evolution of High School pupils' learning evolution, when placed in contact with the concept of entropy in daily situations, throughby activities and didactic texts. Our strategy washas been based on the students' previous conceptions and on the use of the evolutionary process of conceptual development and construction as background to put the developed knowledge. The data was been collected from a group of ten students through pre and post after-tests and we analyzed them us theing contents analysis. technique to analyzed it.Like conclusions, it was possible to verify an improvement was seen ion those concepts inof the majority of the students under consideration.

Keywords: Physics education, Entropy, Constructivism, Conceptual Evolution.

\section{Introdução}

A busca de uma prática pedagógica voltada para um aprendizado mais significativo justifica-se perante a crescente insatisfação com o paradigma tradicional de ensino, que preconiza, basicamente, o repasse de conteúdos de forma acrítica valorizando a memorização apática por parte dos estudantes. Nesse sentido, as pesquisas sobre concepçōes espontâneas ${ }^{3}$ que surgiram há quase três décadas, mostrando a importância de se considerar as idéias prévias acerca de conhecimentos científicos que os alunos levam consigo para a sala de aula, representaram um passo para que o enfoque passivo em que o aluno era visto como receptáculo de conhecimentos, desse lugar a uma abordagem construtivista ${ }^{4}$ de ensino. Atualmente, contudo, o grande problema em se levar esse novo conceito de ensino para a sala de aula, tem sido a dificuldade de elaboração de estratégias de ensino coerentes com os modelos teóricos (Silva e Lattouf, 1996).

\footnotetext{
${ }^{1}$ Mestre em Educação - Faculdade de Educação - Unicamp. E-mail: silviacovolan@yahoo.com.br

${ }^{2}$ Professor Assistente Doutor do Departamento de Metodologia do Ensino da Faculdade de Educação da Unicamp. E-mail: dirceu@unicamp.br

${ }^{3}$ Termos como idéias prévias, concepçôes espontâneas, conteúdo prévio, conceitos prévios, concepçôes alternativas, entre outros, são utilizados como sinônimos para expressar as noções que o individuo tem em relação a determinado fenômeno, e soam distintos das mais aceitas pela ciência formal.

${ }^{4} O$ termo construtivismo, hoje, assume várias conotaçôes, estando presente nos discursos de filósofos, psicólogos e educadores, sendo empregado para designar idéias ou posturas diferentes das tradicionais a respeito do significado da própria aprendizagem, inspirando-se na teoria sobre o desenvolvimento de Piaget (Silva, 1995).
} 
$\mathrm{Na}$ tentativa de subsidiar o trabalho docente buscando superar situaçóes como a citada anteriormente, propomos neste trabalho algumas atividades, organizadas dentro de um minicurso, que foram realizadas em sala de aula com o objetivo de proporcionar aos estudantes um aprimoramento de suas concepçôes. Para tanto, investigamos como esses alunos concebiam idéias sobre sentido dos processos espontâneos, irreversibilidade e entropia.

Pesquisadores da área (Ben-Zvi, 1999; Sichau, 2000) consideram a Física Térmica, especialmente no que se refere ao conceito de energia e leis da termodinâmica, como sendo um tópico "impopular" entre os estudantes e difícil de se trabalhar, por tratar fenômenos em que a matemática que os exprime aparece dissociada do cotidiano vivenciado por esses indivíduos.

Talvez assim, para superar essa dissociação de conceitos intricados por sua natureza própria, poderíamos utilizar a Evolução das idéias do conceito de Entropia e da Física Térmica como um meio de trazer para perto do estudante uma ciência que não se apresenta como algo pronto, mas que se encontra sempre em constante construção.

Assim, especificamente, como problemática desta pesquisa, com base nas discussōes teóricas, pretendíamos compreender a evolução do conceito de entropia para alunos do Ensino Médio utilizando estratégias de ensino fundamentadas em concepções prévias e subsidiadas pela Evolução das idéias da Ciência, dentro de uma abordagem construtivista. Assim, entendemos que o conhecimento não é recebido passivamente, mas é ativamente construído pelo sujeito (Carvalho e Barros, 1998).

O conceito de entropia foi escolhido em face de uma carência de pesquisas, por nós observadas, referentes ao tema e também por acreditarmos na dificuldade que o educador encontra no ensino deste construto, o que se evidencia em relação a outros conceitos dentro da Física Térmica.

Outro aspecto importante a se considerar, conforme Wheatley (1991), refere-se ao fato de que tudo o que se aprende depende dos conhecimentos que já se tinha antes. Nesse sentido, o conhecimento é sempre contextual e indissociável do sujeito. Dentro desta perspectiva, o aluno é visto como um ser em constante transformação pela ação do conhecimento que ele próprio constrói. No que tange, portanto, ao ensino construtivista, desejamos analisar se o aluno seria capaz de superar sua visão espontânea e reelaborar suas concepçōes tendo como base um conhecimento mais distante do seu cotidiano.

\title{
de Entropia. \\ A importância do Processo de Evolução da ciência no Ensino e o conceito
}

Buscando desmistificar a forma como evoluem os conceitos científicos, bem como contribuir para uma mudança de postura diante dos conteúdos, a abordagem e consideração de alguns aspectos da História da Ciência ${ }^{5}$ no Ensino de Ciências, sobretudo no que tange aos seus aspectos mais humanos, seus dilemas e obstáculos, adquire um papel muito importante:

\begin{abstract}
Encarar a Ciência como um produto acabado confere ao conhecimento científico uma falsa simplicidade que se revela cada vez mais como uma barreira a qualquer construção, uma vez que contribui para a formação de uma atitude ingênua diante da ciência. Ao encararmos os conteúdos da ciência como óbvios, as diversas redes de construção edificadas para dar suporte a teorias sofisticadas apresentam-se como algo natural, portanto, de compreensão imediata.
\end{abstract}

(Robilotta, 1988)

\footnotetext{
${ }^{5}$ Não usamos, stricto sensu, a idéia de se tratar a História das Ciências, pois esta é um campo do saber, com métodos e paradigmas próprios. Preferimos de forma mais "branda" nos referirmos ao processo de Evolução das Idéias da Ciência ou à Evolução dos Conceitos da Ciência, como uso de parte dos processos temporais, mesmo com o risco de muitas vezes se reduzir apenas ao processo factual e não aos objetos complexos da História em si mesmo.
} 
No que diz respeito à utilização de alguns aspectos da Evolução das idéias da Ciência como ferramenta para promover a construção dos conhecimentos científicos em classe, pesquisadores em ensino de Física estão certos de sua importância até mesmo porque estudos têm apontado uma semelhança, ainda que muito localizada, entre as concepções alternativas dos estudantes e os modelos científicos que foram dominantes em determinado período histórico nos diversos campos do conhecimento (Driver \& Easley, 1978; Mc Dermott, 1984; Gil-Perez \& Carrascosa, 1985; Sanmarti, N. \& Casadella, J. 1987).

Ainda que as reflexões permitidas pela utilização da Evolução dos conceitos da Ciência no ensino sejam bastante amplas, seu papel, dentro da nossa proposta de pesquisa, esteve voltado ao caráter mais internalista da ciência com os seguintes objetivos: a) servir como pano de fundo na contextualização dos conceitos trabalhados num plano temporal; b) mostrar, quando possível, a partir da análise de dados, obstáculos epistemológicos através da semelhança entre as concepçōes espontâneas dos estudantes e concepçōes relativas a teorias científicas no transcorrer da História; c) utilizar alguns aspectos do processo observado na evolução do conceito, inseridos em textos didáticos com linguagem acessível para o nível dos alunos para reequilibrar as perturbações ${ }^{6}$ geradas pelas atividades.

Desta forma, para dar consistência às interpretações das idéias dos alunos e à construção das atividades, apresentamos de forma muito sintética a Evolução do conceito de Entropia, relacionando-o às leis da termodinâmica.

O processo da elaboração do conceito de entropia foi longo e árduo, iniciou com base nas experiências de Joule, que provaram que a energia mecânica se transformava quantitativamente em calor (Mason, 1964). Nessa época, então, início do século XIX, com o advento da energia a vapor, durante a Revolução Industrial, começa a tomar forma a teoria da Termodinâmica (Coveney \& Highfield, 1993).

Clausius $(1822$ - 1888), foi um dos primeiros cientistas responsáveis pela aproximação da Teoria do Calor e a Teoria Cinética, criando o que hoje conhecemos por Termodinâmica, ao solucionar o problema teórico da compatibilidade entre o conhecido Princípio de Carnot e o Princípio da Conservação da Energia (Pereira Jr., 1997). A equivalência entre calor e trabalho como formas de energia, é a base da Primeira Lei da Termodinâmica, enunciada por Clausius: num processo fisico a energia é sempre conservada, muito embora possa ser transformada de uma forma em outra (Coveney \& Highfield 1993,); ou ainda: Em qualquer sistema fechado (um motor à vapor, por exemplo) o total da energia é constante (Ronan, 1987).

Também, as idéias de Mayer, Carnot, Joule, entre outros, foram incorporadas à teoria dos motores térmicos, por William Thomson (ou Lord Kelvin) (1824 - 1907) em Glasgow e Clausius, em Berlim. Estes dois últimos perceberam que quando os gases e vapores se expandiam contra uma força contrária, realizando trabalho mecânico, uma parcela do calor se convertia em energia mecânica e a outra parte simplesmente se dissipava durante o funcionamento da máquina a vapor (Mason, 1964). Assim, voltando aos estudos de Carnot sobre o motor a vapor, Clausius constata que este havia se enganado quando pensara que o motor trabalharia somente porque seu calórico diminuía de temperatura (Ronan, 1987).

De qualquer modo, apesar da confusão feita entre as teorias do calórico e do calor como movimento, o trabalho de Carnot teve importância no estabelecimento do segundo Princípio da Termodinâmica, que ficou esquecido até 1848, quando foi resgatado por William Thomson (Lord Kelvin) e também por Clausius, por volta de 1850. Importante frisar que ambos anunciaram a Segunda Lei da Termodinâmica quase ao mesmo tempo, mas independentemente.

${ }^{6}$ O sentido dos termos reequilibrar e perturbações são pertinentes à teoria de Piaget (1976). 
Vale lembrar que embora Lord Kelvin, inspirado nos trabalhos de Carnot, chega a descobrir a Segunda Lei da Termodinâmica um pouco antes de Clausius, apesar de seu princípio correto, sua formulação não parece adequada, uma vez que ele adota ainda a teoria do calórico (Silva, 1995). Ainda assim, o enunciado de Kelvin já estabelecia uma assimetria entre trabalho e calor: "nenhuma máquina converte calor em trabalho com eficiência total; alguma energia é sempre perdida para uma região de menor temperatura" (Ferracioli, 2001). Clausius, por sua vez, concluiu a formulação termodinâmica do Princípio de Carnot, conhecida como a Segunda Lei da Termodinâmica afirmando que:

O calor não pode nunca passar de um corpo mais frio para um corpo mais quente sem que ocorram ao mesmo tempo mudanças associadas. Tudo que sabemos em relação à troca de calor entre dois corpos de temperaturas diferentes confirma isso, pois o calor em toda parte manifesta uma tendência em igualar diferenças de temperatura, e conseqüentemente em passar numa direção contrária, isto é, do corpo mais quente para o mais frio.

(Clausius, apud. Aurani, 1986)

Conforme o exposto, é possível perceber que o enunciado de Clausius implica uma assimetria na direção dos processos naturais: calor flui sempre de objetos ou ambientes quentes em direção aos frios (Ferracioli, 2000).

Em seus estudos, Clausius distinguiu os processos reversíveis dos irreversíveis através da noção de "valor de equivalência" de uma transformação. Ao passo que a quantidade de calor diminuía, durante um ciclo de funcionamento da máquina térmica de Carnot, Clausius percebeu a existência de uma porção que permanecia constante no decurso do mesmo ciclo: a quantidade de calor que era transformada em trabalho mecânico, dividida pela temperatura da fonte quente (caldeira), possuía quantitativamente o mesmo valor numérico que a porção de calor dissipada dividida pela temperatura da fonte fria (condensador) (Mason, 1964). Assim, em 1865, denominou esse quociente de entropia’: uma grandeza que aumenta com a dissipação e atinge seu valor mais alto quando todo potencial de realizar trabalho está esgotado. Desse modo, em um processo reversível, a variação de entropia é nula, enquanto que em um processo irreversível a entropia sempre aumenta (Coveney \& Highfield, 1991).

Assim sendo, Clausius, considerando o universo como um sistema fechado, lançou, em 1865, as duas primeiras leis da termodinâmica numa forma cosmológica. A primeira afirmava que a energia total do universo é constante e a segunda afirmava que a entropia total do universo está aumentando em direção a um valor máximo (Coveney \& Highfield, 1991).

$\mathrm{O}$ conceito de entropia também está associado à desordem. Essa desordem molecular foi definida quantitativamente na Termodinâmica Estatística, por Ludwig Boltzmann (1844 - 1906) por volta de 1866 . Vale a pena dizer que isso se deve ao fato de que, no final do século XIX, a teoria mecânica do calor recebeu novo impulso com os trabalhos de Maxwell (1831 - 1879) sobre distribuição de velocidade das moléculas de um gás e com os do próprio Boltzmann sobre a introdução da teoria das probabilidades e da entropia no estudo da teoria cinética dos gases (Silva, 1995).

Maxwell deu uma importante contribuição para a abordagem deste tipo de processo ao descrever o estado de equilíbrio termodinâmico: em 1860, ele propôs como resultado geral que, após uma série de colisōes, a energia cinética das partículas tende a se equalizar (Magie, 1935).

Adotando a linha de raciocínio empregada por Clausius e Maxwell, Boltzmann reconheceu que: Como resultado das colisôes, muitas moléculas adquirirão maiores velocidades, e outras

${ }^{7}$ O nome entropia vem do grego em (em) e trope (transformação) com o objetivo de indicar "algo em transformação". 
obterão menores velocidades, até que finalmente é estabelecida uma distribuição de velocidades entre as moléculas, tal que não seja alterada por novas colisóes (Boltzmann, apud. Pereira Jr., 1997).

Desse modo, a Segunda Lei da Termodinâmica passa a ter uma interpretação de Boltzmann, como significando que, nos movimentos espontâneos de energia, como por exemplo, a conversão de energia mecânica em calor, ou na refrigeração de corpos aquecidos, as moléculas do sistema envolvido tendiam para uma distribuição aleatória de suas energias. Essa distribuição desordenada era a mais provável, enquanto que outras, mais organizadas, possuíam menor probabilidade de ocorrência. Com isso, Boltzmann concluiu que o crescimento espontâneo da entropia de um sistema poderia ser relacionado com o aumento da distribuição ocasional das energias moleculares do mesmo sistema (Mason, 1964).

A interpretação de Boltzmann corresponde a admitir que os estados de maior entropia são os mais prováveis, mas como também considerou que os estados mais prováveis são os de maior desordem, conclui-se que os sistemas evoluem no sentido de uma maior desordem ao mesmo tempo em que a sua entropia aumenta (Gilbert, 1982).

Uma vez apresentada a evolução do conceito, esperávamos que após o ensino os alunos se aproximassem o máximo possível do conceito formal, resguardando o nível cognitivo da escolaridade que estes estão. De fato, não se pode esperar que alunos do nível médio atinjam os conceitos mais elaborados na sua plenitude.

\section{Procedimentos metodológicos da pesquisa e as ações em sala de aula.}

A abordagem metodológica desta pesquisa foi qualitativa quase-experimental (Selltiz et al., 1972), uma vez que os dados foram coletados em um grupo de estudantes do nível médio antes (pré-teste) e depois (pós-teste) de uma intervenção de ensino (mini-curso), onde a qualidade do conteúdo das respostas foi o que configurou o aspecto mais importante desta análise.

Nesse sentido, os estudos qualitativos apresentam, de acordo com Bogdan e Biklen (apud. Ludke \& André, 1986), algumas características, entre as quais podemos citar as que mais se destacam nesta investigação: a) a pesquisa qualitativa tem o ambiente natural como sua fonte direta de dados e o pesquisador como seu principal instrumento; b) os dados coletados são predominantemente descritivos; c) a preocupação com o processo é muito maior do que com o produto.

No caso específico deste trabalho, essas características são bastante pertinentes. Inicialmente, torna-se necessário recolher os dados no ambiente natural onde ocorre o comportamento, uma vez que o contexto de sala de aula em que os alunos se encontram é determinante para o desenvolvimento dos seus conhecimentos e atitudes. O levantamento de informaçōes, através de questionários e anotações feitas pelo pesquisador, revela o caráter descritivo da investigação, pois as informaçôes se apresentam em um contexto dinâmico de relações. Daí, a preocupação com a análise do processo e não apenas com os resultados finais, ainda que estes sejam apenas as balizas do processo e sobre ele recai a síntese final das análises.

Quanto à organização do exame dos dados obtidos utilizamos a análise de conteúdo, entendida como um método de tratamento e análise de informaçôes (...) que se aplica à análise de textos escritos ou de qualquer comunicação (...) reduzida a um texto ou documento (Chizzoti, 1991, p. 98).

Ainda, Bardin (1977), entende a análise de conteúdo como um conjunto de técnicas de análise das comunicaçôes utilizando procedimentos sistemáticos e objetivos de descrição do conteúdo das mensagens. Ressalta ainda, que, antes de tudo, a análise de conteúdo trata-se de um leque de apetrechos (...) adaptável a um campo muito vasto: as comunicaçôes.

Sendo assim, optamos pelo uso da análise temática, que, segundo Bardin (1977), é uma das formas que melhor se adequa à investigação qualitativa, pois consiste em descobrir os 
núcleos de sentido que compõem uma comunicação. Posteriormente, classificamos os dados em categorias de respostas que não foram preestabelecidas, mas, resultaram do agrupamento progressivo dos elementos.

Decidimos criar um conjunto de categorias hierárquicas em função do nível de elaboração das respostas apresentadas pelos estudantes, do nível conceitualmente menos elaborados para o nível mais elaborado. Essa hierarquização foi inspirada no modelo utilizado por outros pesquisadores de ensino de Ciências, tais como Teixeira (1992) e Silva (1995), e permite compor um panorama geral dos acontecimentos no sentido de perceber a evolução individual de cada estudante. Sendo assim, tivemos 3 categorias (A, B e C) no pré-teste e 4, (A, B, C e D) no pós-teste, que passaremos a explicitar a seguir.

\subsection{As categorias do pré e pós-testes.}

O estabelecimento de categorias não é uma tarefa imediata, pois a classificação das respostas [...] impöe a investigação do que cada um deles tem em comum com os outros. O que vai permitir o seu agrupamento e a parte comum existente entre eles (Bardin, 1977).

Nesse processo, as categorias não foram inicialmente definidas, mas elaboradas a partir de um referencial interno (buscando-se as regularidades nas respostas, com base no referencial da Evolução dos Conceitos da Ciência). Desse modo, identificamos três categorias resultantes do exame feito nas seis questôes que constituíram o pré-teste e quatro categorias criadas de forma análoga em relação às questôes do pós-teste. Optamos por usar como referência os conceitos de irreversibilidade e entropia, tal como definidos no item 2, com a ressalva de que alunos do nível médio não devem construir conceitos formais e estruturados na sua plenitude, como os cientistas apresentados, isto é, esperamos que haja uma primeira aproximação das noções dos estudantes às científicas, para serem consideradas satisfatórias.

Após a leitura exaustiva do material, vimos que seria possível conhecer, através do préteste, as noçōes dos alunos no que se refere à assimetria na direção dos processos naturais e ao reconhecimento de processos irreversíveis espontaneamente. Com isso, dividimos o pré-teste em dois grupos de análise: as questôes 1,3 e 5 (respectivamente correspondentes ao caso das barras a diferentes temperaturas, do gás confinado num dos lados da caixa e finalmente a questão do monte de areia), deveriam levantar concepçōes sobre o sentido dos processos espontâneos e as questōes 2, 4 e 6 (canecas com água, gás difundido por todo o volume de uma caixa e areia espalhada pelo terreno), deveriam revelar a compreensão dos alunos acerca dos fenômenos irreversíveis espontaneamente.

Passaremos então, à apresentação das três categorias de respostas definidas no préteste. Atribuímos a nomenclatura A, B e C às categorias de modo que pelo esquema de hierarquização anteriormente mencionado, a categoria $\mathrm{C}$ corresponde ao maior nível de elaboração das respostas enquanto a categoria $\mathrm{A}$ representa o menor nível.

Categoria A: incluímos nesta categoria as respostas de modo geral incoerentes, sem justificativas e carregadas de impressōes do senso comum; Categoria B: agrupamos aqui, os estudantes que apresentaram algumas respostas indicativas de suas noçôes corretas, porém imprecisas acerca do sentido na ocorrência de um processo natural espontâneo mas que não reconhecem os processos reversíveis através de uma ação; ou ainda, aqueles que reconhecem a reversibilidade de alguns processos através de uma ação mas não distinguem o sentido em que ocorre um fenômeno espontâneo; e Categoria C: as respostas agrupadas nesta categoria, embora apresentem indícios de concepçôes do senso comum, assim como nas categorias anteriores, são as mais elaboradas e incluem noção de sentido correto em processos naturais espontâneos, bem como o reconhecimento de fenômenos passíveis de reversão por um caminho não natural. 
Para as categorias do pós-teste, uma pré-análise das respostas fornecidas pelos estudantes permitiu-nos levantar suas concepçôes sobre o sentido dos processos espontâneos (questôes 1,2 , 4, e 5), sobre processos irreversíveis espontaneamente (questão 3, tópicos a e b) e finalmente, se são capazes de diferenciar fenômenos totalmente irreversíveis daqueles passíveis de reversão através de ações (questóes 3 - tópicos b e c, e 5), sendo este último, um aspecto que não foi possível revelar no pré-teste.

Com base nas noções apresentadas pelos alunos, elaboramos desta vez quatro categorias de análise: A, B, C e D (agora as respostas mais consistentes apareceram), que serão apresentadas a seguir. De maneira análoga à categorização das respostas do pré-teste, a categoria $\mathrm{D}$ corresponde ao maior nível de elaboração das respostas, enquanto a categoria A representa o menor nível.

Categoria A: incluímos nesta categoria as respostas de modo geral incoerentes, sem justificativas e carregadas de impressões do senso comum; Categoria B: agrupamos aqui, os estudantes que apresentaram algumas respostas indicativas de suas noçôes corretas, porém imprecisas acerca do sentido na ocorrência de um processo natural espontâneo mas que não reconhecem os processos reversíveis através de uma ação; ou ainda, aqueles que reconhecem a reversibilidade de alguns processos através de uma ação mas não distinguem o sentido em que ocorre um fenômeno espontâneo; Categoria C: as respostas agrupadas nesta categoria, embora apresentem indícios de concepçôes do senso comum, são um pouco mais elaboradas que as anteriores. Incluem noção do sentido correto em processos naturais espontâneos, o reconhecimento de fenômenos passíveis de reversão por um caminho não natural, além de algum reconhecimento na distinção entre fenômenos totalmente irreversíveis e os reversíveis através de uma ação; e Categoria D: nesta categoria, incluímos os alunos que foram capazes de diferenciar, em algumas situações, fenômenos totalmente irreversíveis daqueles passíveis de reversão através de açôes específicas; além disso, de forma direta ou indireta, conseguiram associar aumento da desordem de um sistema a um aumento de entropia do mesmo.

\subsection{O Mini-Curso Proposto:}

Com vistas à coleta de dados que serviram como fonte de análise para a nossa pesquisa, desenvolvemos um mini-curso sobre o conceito de entropia destinado a alunos da $2^{\text {a }}$ série do Ensino Médio, que foi trabalhado no final do $2^{\circ}$ semestre de 2002.

Iniciamos nosso trabalho com uma classe de 29 alunos, mas nossa amostra ficou reduzida a 10 estudantes. A redução do número de alunos deveu-se a problemas inerentes à nossa vontade. Havia na escola atividades de recreação programadas, e muitos alunos já estavam comprometidos com a sua realização. Então a opção mais viável para acompanhar o desenvolvimento da aprendizagem foi a de analisar apenas aqueles que efetivamente estiveram presentes em todos os momentos do mini-curso.

O mini-curso foi estruturado para uma duração máxima de cinco aulas, onde se desenrolaram ações que compreenderam: investigação de concepções dos educandos, discussões acerca de suas respostas, apresentação e discussão de dois textos sobre o conceito de entropia elaborados com linguagem acessível (referência básica do paradidático Quadros, 1996) além de trechos da Evolução das idéias da Ciência (vide anexos 1 e 2). Finalmente, após a apresentação do conceito científico através dos textos, propusemos uma nova intervenção com o auxílio de um questionário, buscando avaliar o crescimento das concepções dos estudantes.

Sistematizando, nos apoiamos para a realização do ensino na proposta apresentada por Wheatley (1991), onde este sugere um tripé para a realização do trabalho em sala de aula em uma perspectiva construtivista: 1 - Tarefas que devem ser desenvolvidas com diferentes estratégias 
acessíveis aos alunos; 2 - Criar grupos cooperativos fazendo com que os alunos trabalhem em pequenos grupos para buscar soluções conjuntas em criar um clima de constantes desafios internamente aos grupos ou no grupo classe; e 3 - Compartilhar as idéias, permitir que os estudantes troquem com a classe os seus métodos, as suas sínteses, as suas conclusões e a busca de consensos.

Associada à proposta apresentada incluímos dois textos para que os alunos pudessem ter um parâmetro de comparação e de reequilibração das suas concepçôes, sem a pretensão de fazer dos textos a "palavra da autoridade". Assim, o uso de textos com elementos históricos pode dar uma visão bastante sólida para o aluno, pois este pode identificar dificuldades parecidas com as suas e assim conseguir seguir o caminho mental necessário para reestruturar as suas concepçôes, como mostraram Saltiel e Viennot (1985), há uma semelhança entre as idéias espontâneas e aquelas de vários pensadores que fizeram a Ciência. Num certo sentido é o que os cientistas fazem quando, ao publicarem as suas idéias, buscam criar debates com a comunidade científica, ou ainda quando buscam a identificação com outros autores.

Esclarecendo mais, os textos em questão foram desenvolvidos com base na literatura da História dos Conceitos e redigidos com linguagem simples, para que alunos do nível médio pudessem compreender. A escolha para a redação dos mesmos foi a evolução temporal dos conceitos e a inserção de aspectos cotidianos dos alunos. Tais textos foram submetidos a quatro especialistas em ensino de Ciências Naturais para serem validados teoricamente, isto é, para que confirmassem as nossas premissas de que os textos eram adequados para alunos do nível médio e que possuíam conceitos precisos. Nessa submissão, foi perguntado sobre a adequação pedagógica e sobre a linguagem. As sugestôes e alteraçôes foram incorporadas. Ainda que pesem as dificuldades inerentes aos conceitos envolvidos e as suas analogias com as situações do cotidiano. Em síntese, buscamos minimizar esses paralelos e fornecer aos alunos situações factíveis para fomentar as discussóes sem, contudo, transformar os textos em enfoque jornalístico.

\subsection{O Desenvolvimento do Mini-Curso:}

A seguir, apresentamos os procedimentos das aulas do mini-curso, bem como um resumo das principais atividades desenvolvidas.

$1^{a}$ Aula: Levantamento das concepções dos estudantes através de questionário. Compreendemos que esta etapa deveria ser realizada individualmente como forma de permitir que cada aluno pudesse expressar suas noçôes. A seguir, apresentamos alguns exemplos das questôes que foram propostas nesta primeira fase do levantamento:

1- Duas barras de aço a temperaturas diferentes $20^{\circ} \mathrm{Ce} 100^{\circ} \mathrm{C}$, são colocadas em contato. O que se verifica após certo tempo? Explique.

2 - Temos duas canecas de aluminio ligadas e revestidas com isopor, uma com 1 litro de água a uma temperatura de $80^{\circ} \mathrm{C}$ e outra, também com 1 litro de água, a uma temperatura de $20^{\circ} \mathrm{C}$ (veja as figuras abaixo).

Encostando uma na outra verifica-se que após certo tempo ambas encontram-se a uma temperatura média de $50^{\circ} \mathrm{C}$.
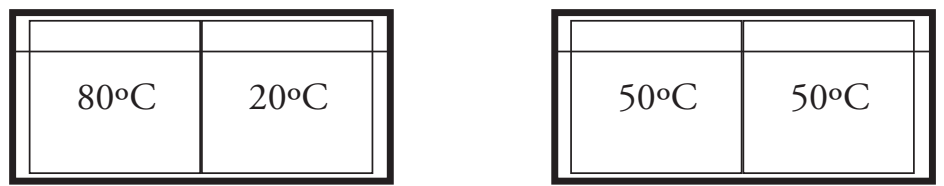

De acordo com o enunciado acima, você acredita que o processo inverso possa ocorrer espontaneamente, ou seja, que as massas de água, ambas agora a $50^{\circ} \mathrm{C}$, voltem às temperaturas que anteriormente eram de $80^{\circ} \mathrm{Ce} 20^{\circ} \mathrm{C}$ ? Justifique. 
Na caixa abaixo, de um lado há um gás e do outro foi retirado tudo que havia, produzindo vácuo. Se retirarmos a separação, o que irá acontecer com as moléculas do gás? Faça desenhos representativos nos espaços abaixo, mostrando como as partículas do gás estavam antes, imediatamente após termos removido a separação e depois de um minuto. Explique com suas palavras o que significam os seus desenhos.

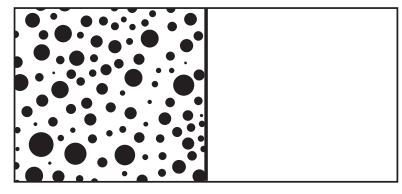

Antes de remover a separação

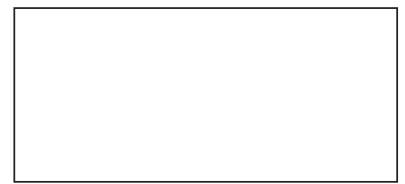

Imediatamente depois de removida a separação

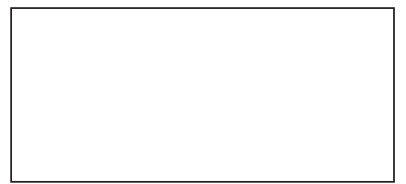

Após 1 minuto

Imagine que em um terreno grande cercado e abandonado há um monte de areia. Com o passar do tempo, mesmo sem a interversão de seres humanos ou mesmo de outros animais, o que você espera que aconteça? Explique. Agora imagine a mesma areia espalhada pelo chão. Você acredita que ela poderia vir a ser reunida sem a intervenção humana e formar um monte novamente? Explique.

2a Aula: Após a superação desta primeira etapa os alunos foram incentivados a debater suas hipóteses em pequenos grupos, o que a nosso ver contribui para uma homogeneização das noções espontâneas expressas anteriormente. O propósito de tal atividade era o de fazer os alunos gerarem perturbações com as suas idéias, pois o debate e o diálogo entre iguais permitem que as concepções possam ser trabalhadas e questionadas sem a presença da autoridade do professor. Desta forma, os alunos podem expressar livremente as suas idéias e confrontá-las entre si. O papel do professor nessa etapa foi o de percorrer os grupos para potencializar o debate e não fornecer a "boa resposta" (Wheatley, 1991).

Assim explicando mais, iniciamos esta segunda aula com a devolução dos pré-testes dos estudantes. Em seguida, foi solicitado que os alunos fossem divididos em pequenos grupos a fim de discutirem as idéias contidas no questionário da aula anterior. Nesse momento, o professor percorreu os grupos ora respondendo às questóes solicitadas, quando essas eram importantes para o avanço das discussões, ora devolvendo a mesma pergunta de uma forma mais específica. Para que não perdêssemos de vista o foco das discussões, após alguns minutos de debate, três questôes mais específicas sobre processos reversíveis e irreversíveis foram propostas para os grupos e solicitado que eles as respondessem por escrito ${ }^{8}$ :

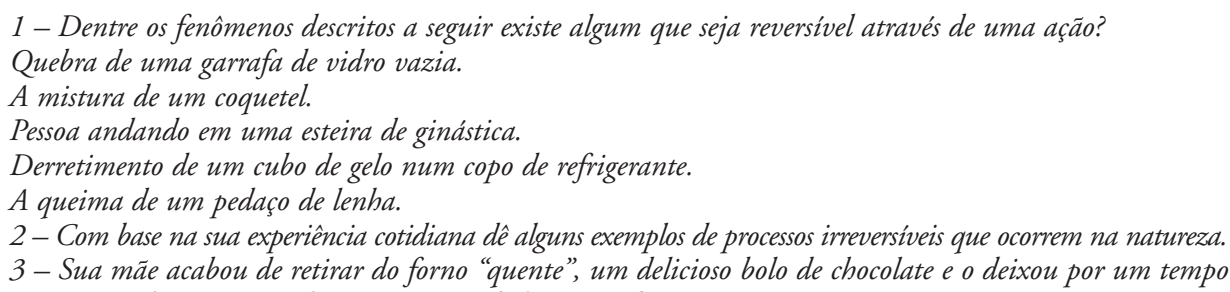
sobre a pia. Então você chega na cozinha e nota que o bolo já está frio. Na sua opinião, por que isso acontece?

Para o fechamento da atividade, cada grupo foi solicitado a relatar suas conclusōes para toda a classe. Nas respostas, observamos diversas manifestações diferentes daquelas expressas no pré-teste, indicando haver um processo de insatisfação com as noções mais primitivas. Também constatamos que as discussões dos alunos chegaram a um nível de "desgaste", isto é, que por eles mesmos não seria possível melhorar as suas concepções. Assim, devido à variedade de explicaçôes que apareceram nas respostas dos estudantes, partimos para a sistematização

\footnotetext{
${ }^{8}$ A necessidade de solicitar a entrega das respostas por escrito cumpre a finalidade de se refletir e sistematizar as idéias, coisa que não se consegue apenas com as respostas orais, sobretudo quando se debate com o grupo classe.
} 
dos conceitos optando por não apresentar apenas uma aula formal, mas resgatar a evolução do conceito de entropia através de textos didáticos elaborados para esse fim.

$3^{a}$ e $4^{a}$ Aulas: A partir desse momento, iniciou-se a formalização dos conceitos através da leitura de textos. $O$ intuito principal dessa fase foi potencializar, entre os estudantes, uma insatisfação com as próprias noçōes e, a partir das reflexōes geradas, permitir que houvesse uma reequilibração de seus sistemas cognitivos através da construção de um novo saber (Castro e Carvalho, 1992). Sendo assim, essas duas aulas destinaram-se à leitura de dois textos onde os estudantes, em grupos, passaram a refletir sobre os conceitos desenvolvidos. Ao término de cada texto, algumas questôes nortearam as discussões. O primeiro texto, intitulado: "Processos Irreversíveis, Leis da Termodinâmica e Entropia" (vide anexo 1), tratou de abordar, dentro de uma linguagem acessível, conceitos de processos reversíveis e irreversíveis, bem como os relacionou às leis da termodinâmica. $\mathrm{O}$ texto foi encerrado com o conceito de entropia, na visão de Clausius, como sendo uma grandeza que aumenta com a dissipação e atinge o seu valor máximo quando todo o potencial de transformação da energia está esgotado. O segundo texto, apresentado na seqüência deste artigo, definiu a entropia do ponto de vista de Boltzmann ("Entropia: rota para a desordem" - anexo 2) para estados microscópicos.

Para nortear as leituras, perguntas específicas de situaçóes do cotidiano foram apresentadas aos alunos para que eles pudessem gerar discussóes no grupo classe. Nessas duas aulas, o professor organizou as discussóes e sistematizou as falas dos alunos na lousa para que ao final fizesse uma organização dos conceitos.

5a Aula: Após as discussões feitas nas aulas anteriores, os alunos responderam individualmente a um questionário contendo seis questões, que buscou avaliar se houve ou não uma evolução conceitual por parte desses estudantes. A seguir, apresentamos algumas questóes que compõem o pós-teste:

Temos duas barras idênticas de ferro: uma a $20^{\circ} \mathrm{C}$ e a outra a $70^{\circ} \mathrm{C}$. Sabendo-se que essas barras são colocadas em contato, o que se verifica após certo tempo? Explique.

Considere as seguintes situações:

Sorvete derretendo;

A Coca-cola que fica choca;

Uma vela que derrete;

Um homem envelhecendo;

Uma planta crescendo;

Café esfriando na xicara.

a-Podemos afirmar que os exemplos acima citados são processos irreversiveis?

$b$-Das situaçóes anteriormente descritas quais representam fenômenos que podem ser revertidos através de uma ação? Qual tipo de ação? Explique.

$c$ - Quais representam fenômenos totalmente irreversiveis?

Seu quarto hoje passou por uma faxina geral: além de limpo, os objetos estão todos em seus devidos lugares. Levando-se em consideração que somente daqui a uma semana ele será arrumado novamente, imagine-se tirando uma fotografia dele por dia, durante estes próximos sete dias.

a-O que você provavelmente irá notar ao final desses sete dias?

$b$ - Podemos dizer, neste caso, que a entropia do sistema quarto aumentou? Explique.

c-Considerando que as modificaçôes ocorridas em seu quarto não foram abruptas, mas gradativas ao longo desses sete dias, é possivel afirmar que a medida da entropia nos três primeiros dias foi menor que no decurso de uma semana inteira? Justifique sua resposta.

Além destas questões, repetimos aqui, de forma idêntica, o problema das moléculas do gás confinadas dentro de uma caixa, anteriormente proposto no pré-teste, com o propósito de verificar como seriam as novas respostas dos estudantes. 


\section{Apresentação e discussão dos dados}

Ao iniciarmos o trabalho com os alunos atentamos às recomendações dos estudiosos da área de ensino de Ciências (Driver, 1988; Santos, 1991, Kesidou e Duit, 1993; Silva, 1995; Castro e Ferracioli, 2002) e procuramos partir de suas pré-concepçōes.

É importante mais uma vez esclarecer que as categorias foram elaboradas levando-se em conta a sua pertinência dentro da nossa pesquisa, ou seja, a partir de uma análise prévia das respostas dos estudantes e adaptadas às intençōes desta investigação. Assim, após a leitura do material, vimos que seria possível conhecer, através do pré-teste, as noçōes dos alunos no que se refere ao sentido dos processos espontâneos e que compreensão estes estudantes teriam acerca dos fenômenos irreversíveis espontaneamente.

No quadro 1 resumimos o número de sujeitos com relação às categorias $\mathrm{A}, \mathrm{B}$ e $\mathrm{C}^{9}$, definidas para o pré-teste.

Quadro 1 - Número de alunos por categoria de análise (Pré-teste).

\begin{tabular}{|c|c|}
\hline Categorias & Número de Alunos \\
\hline A & 3 \\
\hline B & 6 \\
\hline C & 1 \\
\hline
\end{tabular}

O pré-teste, bem como o $2^{\circ}$ momento de nossa intervenção ${ }^{i 0}$, revelou dados, em um certo sentido, semelhantes aos encontrados em trabalhos anteriores (Sciarretta, Stili e Missoni, 1990; Kesidou et al. 1995; Silva, 1995, entre outros), com relação aos conceitos de calor e temperatura. De modo geral, os alunos não fazem distinção clara entre esses dois conceitos; calor (e por vezes também o frio) é expresso em função da teoria do calórico assim como se acreditava até o final do século XVIII:

Não, pois antes uma estava quente e a outra fria (referindo-se à questão das canecas com água); ao entrarem em contato a que estava fria fez com que a quente esfriasse e vice-versa.

Porque o bolo estava no forno (caso do bolo retirado do forno). Foi retirado e transportado para um ambiente com total temperatura oposta. Assim, o bolo vai perdendo a temperatura quente chegando a obter a temperatura onde está - a pia.

Com relação aos dois raciocínios anteriores, Vosniadou (1994) explica que os modelos criados pelos alunos ao interpretarem suas observaçôes sustentam-se em pressupostos ontológicos e epistemológicos. No caso dos fenômenos térmicos, as teorias de domínio dos estudantes sustentam-se, do ponto de vista ontológico, na crença de que os objetos têm propriedades e de que calor e frio são propriedades dos objetos.

No que diz respeito à visão epistemológica derivam da convicção de que as coisas são como aparentam ser e que algo existe apenas se é detectável por nossos sentidos. Sendo assim, a aluna concebe que essa transferência (de calor) pode ocorrer nos dois sentidos, ou seja, tanto da caneca quente para a fria quanto da caneca mais fria para a quente. Isso evidencia sua noção de que os corpos podem também emitir calor frio, já que a caneca fria é capaz de esfriar a que estava quente. Essa interpretação pode lhe parecer plausível, pois não compromete "os efeitos

\footnotetext{
${ }^{9}$ Lembramos que de acordo com a hierarquização das categorias proposta neste trabalho, pode-se dizer que a categoria $A$, representa o menor nivel de elaboração das respostas, enquanto a categoria $C$, representa o maior nivel.

${ }^{10}$ Neste momento, os estudantes em pequenos grupos, discutiram as questôes do pré-teste e apresentaram, por escrito, respostas de três questóes que foram propostas na tentativa de verificar o consenso entre os integrantes de cada grupo.
} 
observáveis”, ou seja, o resultado final, de qualquer forma, continua sendo o equilíbrio térmico atingido pelos corpos envolvidos.

Também a questão do sentido dos processos espontâneos, bem como a irreversibilidade dos mesmos, gera dúvidas e confusões: não é consenso que o aumento de desordem seja uma tendência natural após a ocorrência de fenômenos espontâneos:

O gás se espalha por todo o recipiente (imediatamente após a retirada da separação); ao entrar em contato com o ar (refere-se 1 minuto após) o gás diminui.
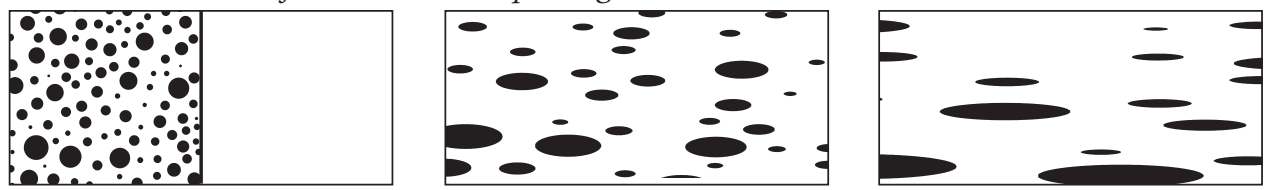

Fig. 1: Esquema do comportamento das moléculas do gás - aluna Cilene

Essas partículas (no caso do gás confinado) irão se juntar e ficarão em tipo de um montinho.

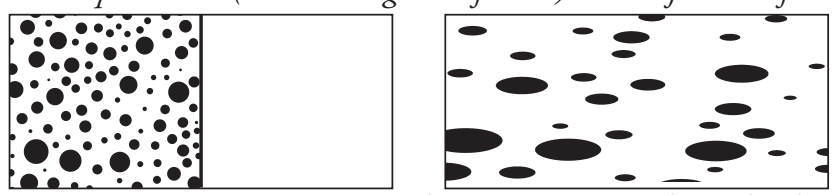

Fig. 2: Esquema do comportamento das moléculas do gás - Aluno Alex

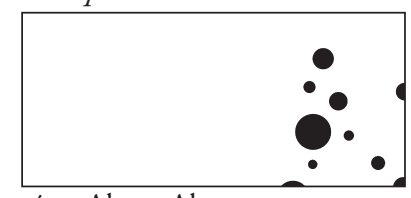

Sim, com a ajuda do vento, ela poderá ser espalhada e logo ajuntada novamente (caso da areia espalhada pelo terreno).

Acredito que sim, pois ela poderá ser levada através do vento em um certo canto, podendo assim, unir-se novamente, formando um novo monte de areia.

Os momentos intermediários do mini-curso, correspondentes aos $2^{\circ}, 3^{\circ}$ e $4^{\circ}$ encontros, foram analisados no sentido de se verificar a tendência das concepções dos estudantes pela introdução de elementos desconhecidos fornecidos pelos textos. Nesses momentos, portanto, as atividades foram todas realizadas em grupos e não foi possível elaborar categorias como fizemos para o pré e o pós-teste.

Sem perder o objetivo de estabelecermos um paralelo entre os dois momentos da nossa intervenção (pré e pós-teste), formulamos este último com situações semelhantes às do pré-teste de modo que as categorias de análise de ambos os testes fossem comparáveis.

Uma pré-análise das respostas fornecidas pelos estudantes através do pós-teste, permitiu-nos levantar suas concepções sobre o sentido dos processos espontâneos, processos irreversíveis espontaneamente e, finalmente, se seriam capazes de diferenciar fenômenos totalmente irreversíveis daqueles passíveis de reversão através de ações.

De modo análogo ao pré-teste, apresentamos abaixo o número de alunos classificados nas categorias A, B, C e D (quadro 2), definidas para o pós-teste.

\begin{tabular}{|c|c|}
\hline Categorias & Número de Alunos \\
\hline A & 1 \\
\hline B & 2 \\
\hline C & 3 \\
\hline D & 4 \\
\hline
\end{tabular}

Quadro 2 - Número de alunos por categoria de análise (Pós-teste) 
As respostas reveladas através do pós-teste apresentaram variações, ora passando pela intuição e pelo senso comum, ora evidenciando noções mais elaboradas. Alguns alunos, por exemplo, não conseguiram estabelecer uma generalização quanto ao sentido dos processos espontâneos; outros, por sua vez, não distinguem fenômenos passíveis de reversão daqueles totalmente irreversíveis:

As duas (considerando as barras de ferro) vão ficar na mesma temperatura após um tempo.

$O$ envelhecimento do homem (reconhecendo este como sendo o único processo irreversivel).

O café esfriando na xicara, pode ser aquecido novamente (referindo-se a este como o único processo reversivel através de uma ação).

No entanto, não podemos deixar de constatar que em relação ao pré-teste houve, de maneira geral, um aumento da qualidade das respostas dos alunos, ainda que alguns argumentos não fossem totalmente precisos:

A barra que estiver mais quente passará calor para a barra que estiver mais fria, igualando a temperatura.

Elas vão trocar energia (referindo-se às barras) em forma de calor e vão se estabilizar ficando à mesma temperatura.

Café esfriando na xicara, pois o café pode ser esquentado e o sorvete pode voltar para o congelador (referindo-se corretamente aos fenômenos listados passiveis de reversão).

A vela que derrete, a Coca-cola choca, o homem envelhecendo e a planta crescendo (reconhecendo corretamente os fenômenos totalmente irreversiveis).

Sim, pois a desordem (entropia) será maior no decurso de uma semana inteira (associando a entropia à desordem no quarto após uma semana).

As particulas estavam dispersas e após a separação (referindo-se à remoção da separação que confinava o gás), elas ficaram mais desordenadas; a entropia aumenta - aqui a aluna consegue associar a dispersão das moléculas do gás a uma maior desordem no sistema e, conseqüentemente, a um aumento de entropia.
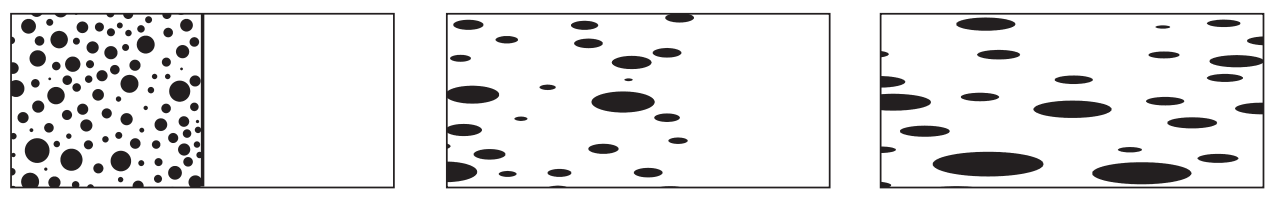

Fig. 3: Esquema do comportamento das moléculas do gás - aluna Sheila

Pelos exemplos de respostas oferecidas acima, é possível notar que alguns estudantes reconhecem o sentido dos processos espontâneos na situação em que o calor flui da barra de maior temperatura para a barra de menor temperatura. Além disso, verificamos em seus discursos a associação do termo energia quando se referem ao calor.

A análise do quadro 3 mostra que sete alunos apresentaram melhorias significativas nas suas elaborações e três mantiveram suas concepções iniciais. Por si só, esse fato mostra que o ensino teve um resultado positivo. Confirma também as dificuldades de se ensinar os conceitos relacionados à termodinâmica, apontados na literatura.

Também observamos que no pós-teste os alunos distinguem mais claramente os fenômenos passíveis de reversão, daqueles totalmente irreversíveis e alguns são capazes de associar o aumento da desordem ao conceito de entropia. 
Para termos uma melhor idéia do comportamento dos participantes, representamos, por meio de posiçōes relativas e setas indicativas de processo, no quadro 3, a evolução de cada um em relação às categorias referentes ao pré e pós-teste.

Comparando as tabelas do pré-teste e pós-teste, pudemos observar a transição de alguns estudantes das categorias menos elaboradas para as mais elaboradas, o que nos leva a concluir que, de alguma forma, os alunos apresentaram uma evolução, ora mais, ora menos significativa no nível de suas concepções em relação aos conceitos que trabalhamos durante o mini-curso.

Quadro 3 - Representação relativa da evolução conceitual dos alunos por categorias.

\begin{tabular}{|c|c|c|}
\hline Categoria & Pré-Test & Pós-Tes \\
\hline & & Thomaz \\
\hline & & Regina \\
\hline & & Anne \\
\hline & & Sheila \\
\hline & & Cilene \\
\hline & Thomaz & Hudson \\
\hline & & Joseane \\
\hline & Anne & \\
\hline & Hélinda & Hélinda \\
\hline & Laís & Laís \\
\hline & Hudson & \\
\hline & Joseane & \\
\hline & Sheila & \\
\hline & Cilene & \\
\hline & Regina & \\
\hline & Alex & Alex \\
\hline
\end{tabular}

\section{Comentários e Considerações finais}

O presente estudo teve o objetivo de analisar a evolução de alunos do nível médio em situação de ensino, quando submetidos ao conceito de entropia, pelo uso de situaçóes do cotidiano e de textos didáticos, em uma perspectiva construtivista.

Para tal, construímos um conjunto de atividades e procedemos a aplicação de dois testes (pré-teste e pós-teste) para avaliarmos o desempenho de 10 alunos. Tais testes foram analisados segundo a metodologia qualitativa de análise de conteúdo, segundo os critérios da qualidade dos conceitos.

Considerando, ainda, o que discutimos sobre a utilização de elementos da Evolução das idéias da Ciência dentro desta investigação, foi possível constatar que em seus discursos, especialmente àqueles relativos ao pré-teste, os estudantes tendem a confundir os conceitos de calor e temperatura, idéia que permaneceu nebulosa até meados do século XVIII, quando Joseph Black, por volta de 1760, estabeleceu a diferença entre esses dois conceitos ao observar que eram necessárias diferentes quantidades de calor para se variar igualmente as temperaturas de substâncias distintas de mesma massa. 
Outra idéia presente nas respostas de alguns alunos é a do calor como uma substância que "sai de um corpo e caminha para outro" - noção integrante da teoria substancialista do calor, surgida no início do século XVIII e que se tornou dominante quase meio século depois, quando Lavoisier adotou o termo calórico para a "substância do calor". Essa concepção permaneceu inabalada até o final do século XVIII, quando Benjamin Thompson (também conhecido como conde Rumford) passa a realizar uma série de experiências que o permite concluir que o calor é uma forma de movimento mecânico.

Acreditamos, no entanto, que os dados obtidos nesta pesquisa poderiam ser melhorados, já que foram tomados quase que imediatamente após um período de possível conflito nas concepções, e se fomos capazes de provocar conflitos, deve haver, segundo Piaget (1976), um período de reequilibração, ou seja, de uma melhor estruturação dos conceitos pelos estudantes. Além do que, foi uma amostra muito reduzida, considerada por nós como adequada para um estudo de natureza exploratória como este, mas que poderia ser expandida e quando melhor controlada, poderia, talvez, revelar novos aspectos que este estudo não mostrou.

Embora não seja possível afirmar que os alunos da nossa amostra tenham adquirido uma sólida concepção que os habilitem para a compreensão das idéias relativas à Segunda Lei da Termodinâmica, ainda assim, consideramos positivo o resultado a que chegamos. Dadas as circunstâncias em que a intervenção ocorreu (praticamente final de ano, época de avaliaçôes e recuperaçôes, campeonatos esportivos), conseguimos em apenas cinco aulas verificar uma melhora nas concepções de sete, de um total de dez estudantes, como mostra o quadro 3.

Finalmente, consideramos que esta investigação contribui para a área de ensino de Ciências, além de fornecer subsídios para estudos complementares. Entendemos que os resultados aqui discutidos, bem como a proposta pedagógica envolvendo o mini-curso para o ensino de entropia, possam ser utilizados por docentes do Ensino Médio como ponto de partida para outras experiências.

\section{Referências}

AURANI, K. M. Ensino de conceitos: estudo das origens da 2a lei da termodinâmica e do conceito de entropia a partir do século XVIII. 1986. 113 p. Dissertação (Mestrado) - Instituto de Física, Faculdade de Educação, Universidade de São Paulo, São Paulo, 1986.

BARDIN, L. Análise de conteúdo. Lisboa: Edições 70, 1997. 225 p.

BEN-ZVI, R. Non-science oriented students and the second law of thermodynamics. International Journal of Science Education, London, v. 21, n.12, p. 1251-1267, 1999.

CARVALHO, A. M. P.; BARROS, M. A. A história da ciência iluminando o ensino de visão. Ciência \& Educação, Bauru, v. 5, n. 1, p. 83-94, 1998.

CASTRO, R. S.; CARVALHO, A. M. P. História da ciência: como usá-la num curso de segundo grau. Caderno Catarinense de Ensino de Física, Florianópolis, v. 9, n. 3, p. 225-237, 1992.

CASTRO, R.; FERRACIOLI, L. Segunda lei da termodinâmica: um estudo de seu entendimento por professores do ensino médio. In: ENCONTRO NACIONAL DE PESQUISA EM ENSINO DE FÍSICA, 8, 2002, Águas de Lindóia. Anais... Águas de Lindóia: SBF, 2002.

Disponível em: http://www.sbf1.if.usp.br/eventos.viii-epef/PDFs/CO19_3.pdf. Acesso em: 20 mar. 2005. 
CHIZZOTTI, A. Pesquisa em ciências humanas e sociais. São Paulo, Cortez, 1991.

COVENEY, P.; HIGHFIELD, R. A flecha do tempo. São Paulo: Siciliano, 1990.

COVOLAN, S. C. T. Utilização dos preceitos da teoria da atividade: a história da ciência como instrumento na construção de conceitos físicos. Caos: Revista Eletrônica de Ciências Sociais, João Pessoa, n. 4, ago. 2002.

Disponível em http://chip.cchla.ufpb.br/caos/04-covolan.html. Acesso em: 05 dez. 2002.

COVOLAN, S. C. T. O conceito de entropia num curso destinado ao ensino médio a partir de concepções prévias dos estudantes e da história da ciência. 2004. 112 p. Dissertação (Mestrado) Faculdade de Educação, Universidade Estadual de Campinas, Campinas, 2004.

DRIVER, R.; EASLEY, J. Pupils and paradigms: a review of literature related to concept development in adolescent science students. Studies in Science Education, Leeds, v. 5, p. 61-84, 1978.

DRIVER, R. Un enfoque constructivista para el desarrollo del currículo en ciencias. Enseñanza de las Ciencias, Barcelona, v. 6, n. 2, p. 109-120, 1988.

FERRACIOLI, L. Aprendizagem, desenvolvimento e conhecimento na obra de Piaget: uma análise do processo de ensino-aprendizagem em ciências. Revista Brasileira de Estudos Pedagógicos, Brasília, DF, v. 80, n. 194, p. 5-18, 2001.

GILBERT, A. Origens históricas da física moderna. Lisboa: Fundação Calouste Gulbenkian, 1982.

GIL-PEREZ, D.; CARRASCOSA, J. Science learning as a conceptual and methodological change. European Journal of Science Education, London, v. 7, n. 3, p. 231-236, 1985.

KESIDOU, S.; DUIT, R. Students' conceptions of the second law of thermodynamics - an interpretative study. Journal of Research in Science Teaching, New York, v. 30, n. 1, p. 85-106, 1993.

KESIDOU, S.; DUIT, R.; GLYNN, S. M. Conceptual development in physics: students' understanding of heat. In: GLYNN, S. M.; DUIT, R. (Ed.). Learning Science in the Schools. Mahwah: Lawrence-Erlbaum, 1995. p. 179-198.

LUDKE, M.; ANDRÉ, M. E. D. Pesquisa em educação: abordagens qualitativas. São Paulo: EPU, 1986. $99 \mathrm{p}$.

MAGIE, W. F. A source book in physics. New York: McGraw-Hill, 1935.

MASON, S. História da ciência: as principais correntes do pensamento científico. Rio de Janeiro: Globo, 1964.

MCDERMOTT, L. C. Research in conceptual understanding of mechanics. Physics Today, New York, n. 37, p. 23-32, 1984.

QUADROS, S. A termodinâmica e a invenção das máquinas térmicas. São Paulo: Scipione, 1996. 96 p. 
PEREIRA JR., A. Irreversibilidade física e ordem temporal na tradição boltzmaniana. São Paulo: Ed. Unesp, 1997.

PIAGET, J. A equilibração das estruturas cognitivas. Rio de Janeiro: Zahar, 1976.

ROBILOTTA, M. R. O cinza, o branco e o preto - da relevância da história da ciência no ensino de física. Caderno Catarinense de Ensino de Física, Florianópolis, v. 5, p. 7-22, 1988. Número especial.

RONAN, C. A. História ilustrada da ciência: a ciência nos séculos XIX e XX. Rio de Janeiro: Jorge Zahar, 1987. v. 4.

SALTIEL, E.; VIENNOT, L. ¿Que aprendemos de las semejanzas entre las ideas históricas y el razonamiento espontaneo de los estudantes ? Enseñanza de las Ciencias, Barcelona, v. 3, n. 3, p. 137-144, 1985.

SANMARTI, N.; CASADELLA, J. Semejanzas y diferencias entre las concepciones infantiles y la evolución histórica de las ciencias: el ejemplo del concepto de fuerza y especialmente del de fuerza de gravedad. Enseñanza de Las Ciencias, Barcelona, v. 5, n. 1, p. 53-58, 1987.

SANTOS, M. E. V. Mudança conceitual na sala de aula. Lisboa: Livros Horizonte, 1991.

SCIARRETTA, M. R.; STILI, R.; MISSONI, M. V. On the properties of materials: common-sense knowledge of Italian students and teachers. International Journal of Science Education, London, v. 12, n. 4, p. 369-379, 1990.

SELLTIZ, C.; JAHODA, M.; DEUTSCH, M. Métodos de pesquisa nas relações sociais. São Paulo: EPU, 1972.

SICHAU, C. Practising helps: thermodynamics, history, and experiment. Science Education, New York, v. 9, p. 389-398, 2000.

SILVA, D. Estudo das trajetórias cognitivas de alunos no ensino da diferenciação dos conceitos de calor e temperatura. 1995. 316 p. Tese (Doutorado) - Faculdade de Educação, Universidade de São Paulo, São Paulo, 1995.

SILVA, D.; LATTOUF, R. Eletricidade: atividade de ensino coerente com um modelo construtivista. Proposiçóes, Campinas, v. 7, n. 19, p. 41-57, 1996. Special Issue: Educação em Física.

TEIXEIRA, O. P. B. Desenvolvimento do conceito de calor e temperatura: mudança conceitual e ensino construtivista. 1992. 183 p. Tese (Doutorado em Educação) - Faculdade de Educação, Universidade de São Paulo, São Paulo, 1992.

WHEATLEY, G. H. Constructivism perspectives on science and mathematics learning. Science Education, New York, v. 75, n. 1, p. 9-21, 1991. 


\section{Anexo 1}

\section{Processos Irreversíveis e leis da termodinâmica}

Os processos irreversíveis são aqueles que possuem um sentido preferencial no tempo, não havendo meios de serem executados "de trás para frente". Quando um mergulhador pula em uma piscina, sua energia ${ }^{I I}$ de movimento (energia cinética) é convertida em calor, aquecendo a água. O processo é irreversível, pois o resfriamento da água não é capaz de fazer com que o mergulhador volte ao trampolim. Também é irreversível o resfriamento de uma xícara de café ou a queima de lenha em uma lareira. Seria possível observar a fumaça voltando pela chaminé, enquanto a sala se resfria e a lenha sendo reconstituída a partir das cinzas?

Podemos citar uma série de processos como esses: copos que se quebram ao cair no chão, pilhas de lanterna que se descarregam, gelo que derrete no copo de refrigerante, enfim. E o que todos eles têm em comum? Eles só ocorrem espontaneamente em um sentido. Estes

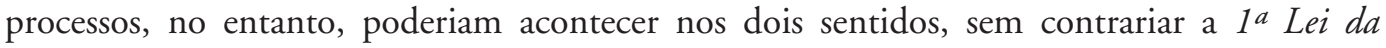
Termodinâmica, isto é, sem violar o princípio da conservação da energia. Este princípio foi enunciado primeiramente por Julius F. Mayer (1814 - 1878) sob a seguinte forma:

Quando uma quantidade de energia de qualquer natureza desaparece numa transformação, então se produz uma quantidade igual em grandeza de uma energia de outra natureza.

(Gilbert, p. 234, 1982)

Se, no processo do movimento mecânico, a energia do corpo diminui devido à ação das forças de atrito (por exemplo, um tijolo deslizando sobre uma superfície), isso ocorre porque esta se transforma em calor; os corpos que se atritam se aquecem. Transforma-se em calor a energia elétrica, a energia da luz, a energia das reaçóes químicas etc. Qualquer forma de energia, no processo de transformação, pode passar através de muitas formas de energia, contudo, o resultado final de todas essas transformações inevitáveis é a energia térmica. Embora, de acordo com a $1^{\text {a }}$ Lei, a energia seja conservada enquanto ocorrem as transformações, ela perde a sua utilidade à medida que o calor se difunde pelo ambiente.

Voltando ao questionário introdutório deste curso, veja, por exemplo, o caso das canecas com o mesmo volume de água: uma certa quantidade de energia térmica $\left(\right.$ calor $^{12}$ ) passa da água mais quente $\left(\mathrm{a} 80^{\circ} \mathrm{C}\right)$, para a outra mais fria $\left(\mathrm{a} 20^{\circ} \mathrm{C}\right)$ até que ambas se encontrem à mesma temperatura $\left(50^{\circ} \mathrm{C}\right)$, isto é, até que atinjam o equilíbrio térmico. Como o calor cedido por uma caneca foi recebido pela outra, garante-se aí a conservação da energia. No entanto, não há como reverter espontaneamente esse processo. A energia trocada entre as canecas, na forma de calor, não pode ser colocada em uso novamente, tornando-se irreversível.

A $2^{a}$ Lei da Termodinâmica expressa um sentido para os processos naturais espontâneos. Existem algumas formas diferentes de se enunciar esta Lei e uma delas, apresentada em meados do século XIX, por Rudolf Clausius (1822 - 1888) em um trabalho publicado em 1850, dizia ser impossível haver transferência espontânea de calor de um objeto frio para outro mais quente. Nas palavras do próprio Clausius:

\footnotetext{
${ }^{11}$ Etimologicamente, Energia é um vocábulo formado por em (em, dentro) e ergon (ação), ou seja, ação interior. Esta palavra aparece pela primeira vez nos escritos de Kepler $(1571$ - 1630) e somente pouco mais de um século depois é que este conceito aparece associado ao de trabalho, o que acontece em 1755 nos trabalhos de Euler (1707 - 1783).

${ }^{12}$ Vale lembrar que Calor é energia em trânsito que flui de um corpo para outro devido exclusivamente a uma diferença de temperatura entre eles, sempre no sentido do corpo de maior temperatura para o de menor temperatura. O fluxo de energia térmica (calor) cessa imediatamente depois de estabelecido o equilíbrio térmico entre os corpos, isto é, até que suas temperaturas tornem-se iguais.
} 
A Entropia no Ensino Médio...

O calor não pode nunca passar de um corpo mais frio para um corpo mais quente, sem que ocorram mudanças associadas. Tudo o que sabemos em relação às trocas de calor entre dois corpos de temperaturas diferentes confirma isso, pois o calor em toda parte manifesta uma tendência em igualar diferenças de temperatura e conseqüentemente, em passar numa direção contrária, isto é, do corpo mais quente para o mais frio.

("From Watt to Clausius", 1971, apud. Aurani, 1986)

Observe a condição "espontânea". Em sua geladeira, por exemplo, a todo instante, calor é transferido dos tubos em seu interior (no congelador), à sua vizinhança (cozinha), necessitando, para isto, que o refrigerador esteja ligado à tomada e funcionando, ou seja, consumindo energia elétrica. Sendo assim, o processo não é espontâneo, mas sim induzido. Da mesma forma, retornando ao exemplo das canecas com água, ambas a $50^{\circ} \mathrm{C}$, seria necessária uma "contribuição externa", uma "dose de energia" para que estas voltassem à condição inicial de $80^{\circ} \mathrm{C}$ e $20^{\circ} \mathrm{C}$. Uma delas deveria receber energia térmica (calor) de uma fonte externa, enquanto a outra deveria perder energia térmica até que sua temperatura voltasse a ser $20^{\circ} \mathrm{C}$.

Como saber se um processo viola ou não a $2^{a}$ Lei da Termodinâmica? Em outras palavras: como decidir se esse processo está na mão certa e é um processo natural ou não? Clausius, em 1865, distinguiu processos reversíveis de processos irreversiveis e introduziu o conceito de entropia: uma grandeza que aumenta com a dissipação e atinge o seu valor máximo, quando todo o potencial de transformação da energia está esgotado. Sendo assim, todo processo que ocorre naturalmente deve ser acompanhado de um aumento de entropia.

\section{Anexo 2}

\section{Entropia: a rota para a desordem}

Num dos exemplos de processos irreversíveis, citados no texto anterior, vimos o caso de um tijolo que desliza numa superfície com atrito e sua energia cinética converte-se em calor. Com isso, é possível pensar que o movimento inicialmente ordenado de suas partículas vai aos poucos sendo transformado num movimento caótico, desordenado de suas moléculas constituintes. Essa transição ordem - desordem caracteriza todos os processos irreversíveis, e está relacionada ao conceito de entropia. O termo entropia é geralmente associado à desordem nos processos. Este é o significado da imperfeição expressa na 2a Lei da Termodinâmica: a desordem total do Universo sempre aumenta. As campanhas de economia de energia, intensificadas com a crise, não têm sentido quando vistas sob a luz da $1^{\text {a }}$ Lei da Termodinâmica, pois se a energia total do Universo é sempre constante, porque economizar? A 2a Lei explica: em um processo irreversível, a energia transformada em calor é irrecuperável espontaneamente.

Para entender melhor a associação do conceito de entropia com a desordem, vamos utilizar um exemplo. Suponha que temos água azul, com tinta e água pura, sem tinta, em um tanque, com uma separação entre elas. Removendo delicadamente a separação, a água vai gradativamente misturando-se e, ao final, temos uma água azulada, com a tinta uniformemente distribuída. Mesmo que observemos a mistura por um longo período de tempo, ela não irá separar-se espontaneamente.

Vamos ver o que ocorreu com as moléculas neste exemplo: suponha que tenhamos filmado a mistura de água azul e incolor. Passar o filme ao contrário nos remete a uma situação absurda: uma separação espontânea das águas azul e incolor. Dando um zoom neste filme, a fim de assistirmos a cada colisão molecular, perceberíamos moléculas de dois tipos, "brancas" e "azuis", movendo-se aleatoriamente. Passando o filme no sentido correto, vemos, no início, 
as moléculas distintas separadas, de um lado e do outro. Estão em grande agitação, bilhões e bilhões delas e, após a retirada da separação, vão se misturando aos poucos até que a água esteja azulada, mais ou menos uniformemente.

Concentremos nossa atenção em uma colisão específica: uma molécula azul vem daqui, uma branca vem de lá, chocam-se e tomam direções distintas. Esse pequeno pedaço do filme, exibido ao contrário, vai mostrar moléculas colidindo com seus movimentos invertidos e tudo estará de acordo com as leis da Física. As leis da colisão molecular são reversíveis, mas como é possível que um processo irreversível (no caso, a mistura das águas de diferentes cores), possa ser decomposto em uma sucessão de processos totalmente reversíveis? Para entender esta questão, devemos imaginar que, se o movimento das moléculas é aleatório, não existe um comportamento preferencial. As moléculas vão colidindo, vindo de quaisquer direções, e após muitas dessas colisões espera-se que fiquem uniformemente distribuídas. O filme visto ao contrário mostra as colisões invertidas, e uma a uma parecem razoáveis. Só que o passar do tempo mostra que vão se separando, brancas de um lado e azuis do outro. O estranho é que as moléculas parecem escolher, preferencialmente, as colisões que conduzem à separação e isso seria como se "uma força superior" selecionasse, dentre as possíveis colisões, aquelas capazes de realizar a separação, ou seja, um processo nada natural. A essência da irreversibilidade é uma tendência natural à desordem.

Poderíamos pensar então, que a diminuição da entropia não é proibida, mas somente pouco provável. Com apenas poucas moléculas brancas e azuis em uma caixa não causaria tanta estranheza se, em alguns momentos, ocorresse a separação, mas se o número de moléculas é muito grande, a chance de ocorrer uma separação é nula na prática: pode ser considerada impossível.

Essa desordem molecular foi definida quantitativamente na Termodinâmica Estatística, por Ludwig Boltzmann (1844 - 1906), por volta de 1866. Importante dizer que isso se deve ao fato de que, no final do século XIX, a teoria mecânica do calor recebeu novo impulso com os trabalhos de Maxwell (1831 - 1879) sobre distribuição de velocidade das moléculas de um gás e com os do próprio Boltzmann sobre a introdução da teoria das probabilidades e da entropia no estudo da teoria cinética dos gases.

Maxwell deu uma importante contribuição para a abordagem deste tipo de processo ao descrever o estado de equilíbrio termodinâmico: em 1860, ele propôs como resultado geral que, após uma série de colisões, a energia cinética das partículas tende a se equalizar.

Adotando a linha de raciocínio empregada por Clausius e Maxwell, Boltzmann reconheceu que:

Como resultado das colisôes, muitas moléculas adquirirão maiores velocidades, e outras obterão menores velocidades, até que finalmente é estabelecida uma distribuição de velocidades entre as moléculas, tal que não seja alterada por novas colisóes.

(Boltzmann, apud. Pereira Jr., 1997, p. 43)

Desse modo, a Segunda Lei da Termodinâmica passa a ter uma interpretação de Boltzmann, como significando que, nos movimentos espontâneos de energia, como por exemplo, a conversão de energia mecânica em calor, ou na refrigeração de corpos aquecidos, as moléculas do sistema envolvido tendiam para uma distribuição aleatória de suas energias. Essa distribuição desordenada era a mais provável, enquanto outras mais organizadas, possuíam menor probabilidade de ocorrência. Com isso, Boltzmann concluiu que o crescimento espontâneo da entropia de um sistema poderia ser relacionado com o aumento da distribuição ocasional das energias moleculares do mesmo sistema. A primeira formulação do conceito de 
entropia, no entanto, não explicitava uma conexão com estados microscópicos. Sua definição era exclusivamente aplicada ao comportamento global ou macroscópico. Como vimos, a entropia de um sistema aumenta quando este recebe calor de sua vizinhança, e sua relação com a escala microscópica foi feita por Boltzmann. Nas palavras do próprio Boltzmann:

A relação entre a Segunda Lei da Termodinâmica e a teoria das probabilidades foi inicialmente mostrada quando eu provei que uma demonstração analitica desta Lei pode ser fundamentada apenas a partir da teoria das probabilidades. [...] podemos calcular o estado de equilíbrio investigando a probabilidade de diferentes possiveis estados do sistema. O estado inicial será, na maioria dos casos, muito improvável e, a partir dele, o sistema irá evoluir em direção a estados mais prováveis, isto é, ao estado de equilíbrio do calor. Se aplicarmos isto na Segunda Lei, podemos relacionar a quantidade que comumente designamos como entropia com a propriedade do estado atual. Pensando num sistema isolado de corpos que não troca energia com o meio externo, por exemplo, um corpo de alta temperatura e outro de baixa temperatura, colocados em contato e isolados do exterior, permitindo-se a troca de calor somente entre eles (...) O sistema de corpos que pensamos pode ter no início qualquer estado; através da troca entre os corpos, este estado muda; de acordo com a Segunda Lei esta mudança deve sempre ocorrer de modo que a entropia de todos os corpos aumente cada vez mais; o sistema de corpos caminhará de um estado mais improvável para um estado mais provável.

(Magie, 1935)

O grande trabalho de Boltzmann foi mostrar que as duas definições, aparentemente distintas, são equivalentes. Quando um sistema recebe calor, aumenta a agitação de suas partes constituintes e conseqüentemente aumenta sua desordem microscópica.

Nota: As citaçôes dos textos 1 e 2 encontram-se nas referências deste artigo, item 6 . 
